\title{
Development of thyroid gland and ultimobranchial body cyst is independent of p63
}

\author{
Takashi Ozaki $^{1,2}$, Kunio Nagashima ${ }^{3}$, Takashi Kusakabe ${ }^{1, *}$, Kennichi Kakudo ${ }^{2}$ and Shioko Kimura ${ }^{1}$
}

The ultimobranchial body (UBB) and thyroid primordium are the origins of the thyroid gland that fuse around embryonic day 14.5 of mouse gestation, ultimately giving rise to calcitonin-producing $C$ cells and thyroglobulin-producing follicular cells, respectively. A homeodomain transcription factor NKX2-1 is expressed both in the UBB and the thyroid primordium, and is critical for development of the thyroid gland. In this study, the role of p63 in development of UBB and the thyroid gland was analyzed by histological, immunohistochemical, and electron microscopic analyses using mice with various combinations of Nkx2-1 and p63 wild-type, heterozygous, and null alleles. In the absence of p63, a normal thyroid gland develops, as revealed by expression of thyroglobulin and calcitonin, thus showing that p63 is not required for thyroid development. However, in mice carrying the Nkx2-1-null allele, the UBB remains as a cystic vesicular structure and/or in nested patterns consisting of p63-positive cells surrounding the vesicle and undifferentiated immature cells with occasional cilia lying inside. The cystic UBB was present even in the Nkx2-1;p63 double-null mice. The structure and p63 expression pattern of the UBB cyst strikingly resemble the solid cell nest. These results show that in the absence of NKX2-1, UBB becomes cystic independent of p63, which is likely the origin of SCN.

Laboratory Investigation (2011) 91, 138-146; doi:10.1038/labinvest.2010.137; published online 9 August 2010

KEYWORDS: electron microscopy; histochemical analysis; knockout mouse; NKX2-1; solid cell nest; undifferentiated cells

The thyroid gland of mammals has two distinct cell types: follicular cells and C cells. ${ }^{1-4}$ The follicular cells are derived from the thyroid primordium, outpocketing of the foregut endoderm that loses its connection to the foregut tube and subsequently descends in front of the pharyngeal gut as a bilobed diverticulum. The follicular cells eventually synthesize and secrete thyroid hormones. In contrast, $\mathrm{C}$ cells, or parafollicular cells are derived from the ultimobranchial body (UBB) that migrates from the fourth pharyngeal pouch to which neural crest cells have invaded. The UBB fuses with the thyroid primordium around mouse embryonic day (E) 14.5, and the cellular components of the UBB disseminate within the thyroid, ultimately giving rise to the calcitonin-producing C cells. ${ }^{1-5}$ From the analogy to chick ultimobranchial C cells in the ultimobranchial gland, which express neuronal markers $^{6}$ and extend long neurite-like processes when cultured, ${ }^{7}$ it is generally believed that the $\mathrm{C}$ cells in mammals also originate from the neural crest cells. However, it was recently shown that murine thyroid $\mathrm{C}$ cells are derived from the endodermal epithelial cells of the fourth pharyngeal pouch that expresses E-cadherin and do not originate from the neural crest cells. ${ }^{8}$

NKX2-1 (TTF1, TITF1, T/EBP, NKX2.1 $)^{9,10}$ is a homeodomain transcription factor that is critical for the genesis of the thyroid, lung and ventral forebrain. ${ }^{11}$ It is also essential for the regulation of lung and thyroid-specific expression of genes, the latter of which includes those encoding thyroglobulin and thyroid peroxidase. ${ }^{2,12}$ NKX2-1 is expressed in the thyroid primodium and it is required for the maintenance of ordered architecture and function of the differentiated thyroid. ${ }^{13}$ NKX2-1 is also expressed in the UBB rudiment, ${ }^{5,11,14,15}$ and is responsible for the survival of the UBB cells and their dissemination into the thyroid diverticulum. ${ }^{5}$ In Nkx2-1-null mice, the thyroid primordium starts degenerating around E10.5 before the commencement of its caudal migration ${ }^{16}$ while the UBB remains as a cystic vesicular structure after NKX2-1-positive cells disintegrate. ${ }^{5}$ This vesicular structure is lined by a monolayer of p63negative cells, surrounded by a cluster and/or single layer of p63-positive cells. ${ }^{5}$ The vesicular structure resembles the solid

\footnotetext{
${ }^{1}$ Laboratory of Metabolism, National Cancer Institute, National Institutes of Health, Bethesda, MD, USA; ${ }^{2}$ Department of Pathology, Wakayama Medical University, Wakayama City, Wakayama, Japan and ${ }^{3}$ Electron Microscopy Facility, Advanced Technology Program, SAIC-Frederick, NCI-Frederick, Frederick, MD, USA Correspondence: Dr S Kimura, PhD, Laboratory of Metabolism, National Cancer Institute, Building. 37, Room 3106, Bethesda, MD 20892, USA. E-mail: kimuras@mail.nih.gov

${ }^{*}$ Current address: Department of Pathology, Aizu Chuo Hospital, the Onchikai Foundation, Aizu-wakamatsu, Fukushima 965-8611, Japan Received 8 April 2010; revised 7 June 2010; accepted 9 June 2010
} 
cell nests (SCNs) described in humans that contain both solid cell proliferation and follicular-like structures, and has been considered to be the embryonic remnants of the UBB. ${ }^{17-20}$ $\mathrm{SCN}$ s are reported to be found in normal human fetal thyroid with approximately $32.5 \%$ in multi-step sections and $87.5 \%$ in serial sections. ${ }^{21}$

P63 is a member of the p53 tumor-suppressor family, which consists of several isotypes having full-length (TAp63) and $\mathrm{N}$-terminal truncated forms $(\Delta \mathrm{Np} 63)$ as well as having three alternative splicing at the C-terminus $(\alpha, \beta$, and $\gamma){ }^{22}$ TAp63 $\alpha$ is the predominant isoform expressed in human thyroid cancer specimens and cell lines, while normal human thyroids do not express p63. ${ }^{23-25} \mathrm{P} 63$ is used as a marker for the main cells of the SCNs in humans. ${ }^{18-20,24} \mathrm{P} 63$ is also expressed in a subset of papillary thyroid carcinomas and/or Hashimoto's thyroiditis, often associated with SCN, suggesting a possible link between p63 expression, papillary thyroid cancer, Hashimoto's thyroiditis, and SCN. ${ }^{18,25-27}$

In this study, the role of p63 in thyroid development and the nature of UBB cysts were examined using embryos with various combinations of $p 63$ and Nkx2-1 alleles (wild-type, heterozygous, and null) by histological and immunohistochemical methods, and electron microscopy (EM). The results showed that p63 is not required for thyroid development and the UBB rudiment remains as a cystic and/or vesicular structure even without $N k x 2-1$ nor $p 63$ alleles, which consists of one layer of cells that seem to be very poorly differentiated.

\section{MATERIALS AND METHODS}

\section{Animals}

p63(+ I-);Nkx2-1 $(+/-)$ mice (C57BL/6J background) were established by crossing Nkx2-1(+I-) mice ${ }^{11}$ with $p 63(+/-)$ mice, both of which had been backcrossed six times to C57BL/6J mice. The $p 63(+/-)$ mice were produced by mating $p 63(f l / f l)$ mice (kindly provided by Dr Alea Mills ${ }^{28}$ ) with EIIa-Cre transgenic mice. ${ }^{29}$ Animals were maintained under conditions outlined in the 'Guide for the Care and Use of Laboratory Animals' by the National Institutes of Health. Different genotypes of embryos in nine combinations were obtained at embryonic day (E) 12.5, 14.5, 17.5, and 18.5 by intercrossing Nkx2-1(+I-);p63(+I-) mice. A noon of the day when a vaginal plug was observed was considered as E 0.5. The genotypes of embryos used in this study were as follows (tentative name shown in the parenthesis); p63 $(+I+) ; N k \times 2-1(+I+)$ (wild-type), p63( +I+ );Nkx2$1(+/-)(N k x 2-1-\mathrm{Ht}), p 63(+/+) ; N k \times 2-1(-/-)(N k \times 2-1-$ null), $\quad$ p63(+I-);Nkx2-1 $(+/+) \quad(p 63-\mathrm{Ht}), \quad$ p63 $(+/-)$; Nkx2-1 (+I-) (p63;Nkx2-1-dHt), p63(+I-);Nkx2-1(-I-) (p63-Ht;Nkx2-1-null), p63(-I-);Nkx2-1(+I+) (p63-null), p63(-I-);Nkx2-1(+I-) (p63-null;Nkx2-1-Ht), and p63 $(-/-) ; N k x 2-1(-/-)$ (p63;Nkx2-1-d null).

Genotyping was performed by PCR using DNAs isolated from yolk sacs or tails with the following conditions: 1 cycle for $3 \mathrm{~min}$ at $94^{\circ} \mathrm{C}, 30$ cycles for $30 \mathrm{~s}$ at $94^{\circ} \mathrm{C}, 15 \mathrm{~s}$ at $60^{\circ} \mathrm{C}$,
$15 \mathrm{~s}$ at $72{ }^{\circ} \mathrm{C}$, and $1 \mathrm{cycle}$ for $5 \mathrm{~min}$ at $72^{\circ} \mathrm{C}$. The primers used were $5^{\prime}$-GGCGAGCGGCATGAATATGA- $3^{\prime}$ (forward) and $5^{\prime}$-TCTTGTAGCGGTGGTTCTGGA-3' (reverse) for $N k \times 2-1$ wild-type allele, and $5^{\prime}$-TCGCCTTCTATCGCCTTCTTGA- $3^{\prime}$ was paired with the reverse primer for the detection of the Nkx2-1 targeted allele. The primers for detection of $p 63$ $(+/-)$ allele were $5^{\prime}$-CAGAGGAGGCAACACAGGATAGA- $3^{\prime}$ and $5^{\prime}$-CCGGGGGATCCGAATTCATCGA- $3^{\prime}{ }^{28}$ The loxP sites of $p 63(\mathrm{fl} / \mathrm{fl})$ allele flank exons in the DNA-binding domain of p63, thus rendering all isotypes of p63 inactive in the presence of active Cre recombinase. ${ }^{28}$

\section{Histopathological Examination}

Histological analysis was carried out using at least three embryos or adult thyroids from each genotype and/or developmental stage. A whole embryo or a cervical region of an adult mouse containing the thyroid, larynx, and trachea was dissected, fixed in $4 \%$ paraformaldehyde in $0.1 \mathrm{M}$ phosphate-buffered saline (PBS) at $4{ }^{\circ} \mathrm{C}$ overnight, dehydrated, and embedded in paraffin. Serial sections of $3 \mu \mathrm{m}$ thickness were prepared, which were treated with xylene and graded ethanol, and were stained with hematoxyline and eosin (H\&E). Disruption of the $p 63$ gene was confirmed by the presence of aplastic skin in $p 63(-/-)$ mice from E14.5 to postpartum as described. ${ }^{30}$

\section{Immunohistochemistry}

Sections were treated with $1 \%$ hydrogen peroxide in methanol for $30-45 \mathrm{~min}$ to block endogenous peroxidase activity, followed by rinsing three times for $10 \mathrm{~min}$ each with PBS. Epitope retrieval was carried out by heating sections at $100{ }^{\circ} \mathrm{C}$ for $3 \mathrm{~min}$, five times using a microwave oven in $10 \mathrm{mM}$ citrate buffer, $\mathrm{pH}$ 6.0, followed by cooling for $30 \mathrm{~min}$ at room temperature, and washing in PBS. Sections were then treated with 5\% skim milk in PBS for $15 \mathrm{~min}$ to block nonspecific protein binding. Incubation with primary antibody was carried out overnight at $4{ }^{\circ} \mathrm{C}$ in a humidified chamber using the following antibodies: anti-p63 antibody (mouse monoclonal, 1:1000 dilution; BD Biosciences, San Diego, CA, USA), anti-TTF-1 antibody (mouse monoclonal, 1:1000 dilution; DAKO, Carpinteria, CA, USA), anti-SOX10 antibody (rabbit polyclonal, 1:1000 dilution; Abcam, Cambridge, MA, USA), anti-Nestin antibody (rabbit polyclonal, 1:1000 dilution; Abcam), anti-NSE antibody (goat polyclonal, 1:200 dilution, DAKO), anti-S-100 antibody (mouse monoclonal, 1:3000 dilution, Abcam), and anti-calcitonin antibody (rabbit polyclonal, 1:1000 dilution, ICN, Irvine, CA, USA). After washing in $0.01 \mathrm{M}$ PBS, the sections were treated using labeled streptavidin-biotin method (LSAB2 SystemHRP, ready-to-use, DAKO) or the ABC method with commercially available kit (Vector Laboratories, Burlingame, CA, USA) according to the manufacturer's instructions. Immunocomplexes were visualized with $3,3^{\prime}$-diaminobenzidine tetrahydrochloride (Sigma, St Louis, MO, USA). 


\section{Electron Microscopy}

The tissue sample preparation for the EM analysis has been described in a great detail. ${ }^{31}$ Briefly, mouse tissue was fixed in formaldehyde (4\%) and glutaraldehyde (2\%) in cacodylate buffer (0.1 M, pH 7.4) (Tousimis, Rockville, MD, USA) followed by a post-fixation in $1 \%$ osmium in same buffer. The tissue was en bloc stained in $0.5 \%$ uranyl acetate in acetate buffer $(0.1 \mathrm{M} \mathrm{pH} 4.5)$ and dehydrated in a graded ethanol $(35,50,70,95$, and $100 \%)$ and propylene oxide. The infiltration was carried out in an equal mixture of epoxy resin (Embed 812, Electron Microscope Sciences, Fort Washington, PA, USA) and propylene oxide overnight. The tissue was embedded in a pure epoxy resin and cured in $55^{\circ} \mathrm{C}$ oven. Thin sections were mounted on copper grids and stained in uranyl acetate and lead citrate. The grids were examined in the EM (Hitachi H7600, Tokyo, Japan) operated at $80 \mathrm{kV}$ and digital images were taken by CCD camera (AMT, Danvers, MA, USA).

\section{RESULTS}

We previously showed using Nkx2-1-null mice that the thyroid primordium disintegrates in the absence of NKX21. ${ }^{11,16}$ As p63 is used as a marker for the SCN in humans that is considered to be embryonic remnant of $\mathrm{UBB},{ }^{19,20,23}$ the role of p63 in development of UBB and/or thyroid was examined using mice with various combinations of $p 63$ and Nkx2-1 alleles (wild-type, $\mathrm{Ht}$, and null). The presence of UBB was confirmed in all genotyped mice at E12.5 (Figure 1). The UBB was composed of columnar cells having high nucleus/ cytoplasm ratio, which configured the tubular or cystic patterns. At this gestational stage, the size of UBB was not significantly different among wild-type (Figure 1a), Nkx2-1-Ht, (Figure 1d) and Nkx2-1-null mice (Figure 1g) as previously described. ${ }^{5}$ Similarly, p63 did not seem to have a significant effect on the size of UBB (Figures 1a-f). In contrast, the UBB appeared to look slightly smaller in $p 63$ and $N k x 2-1$-doublenull mutants (Figure 1i). All the UBBs were histologically
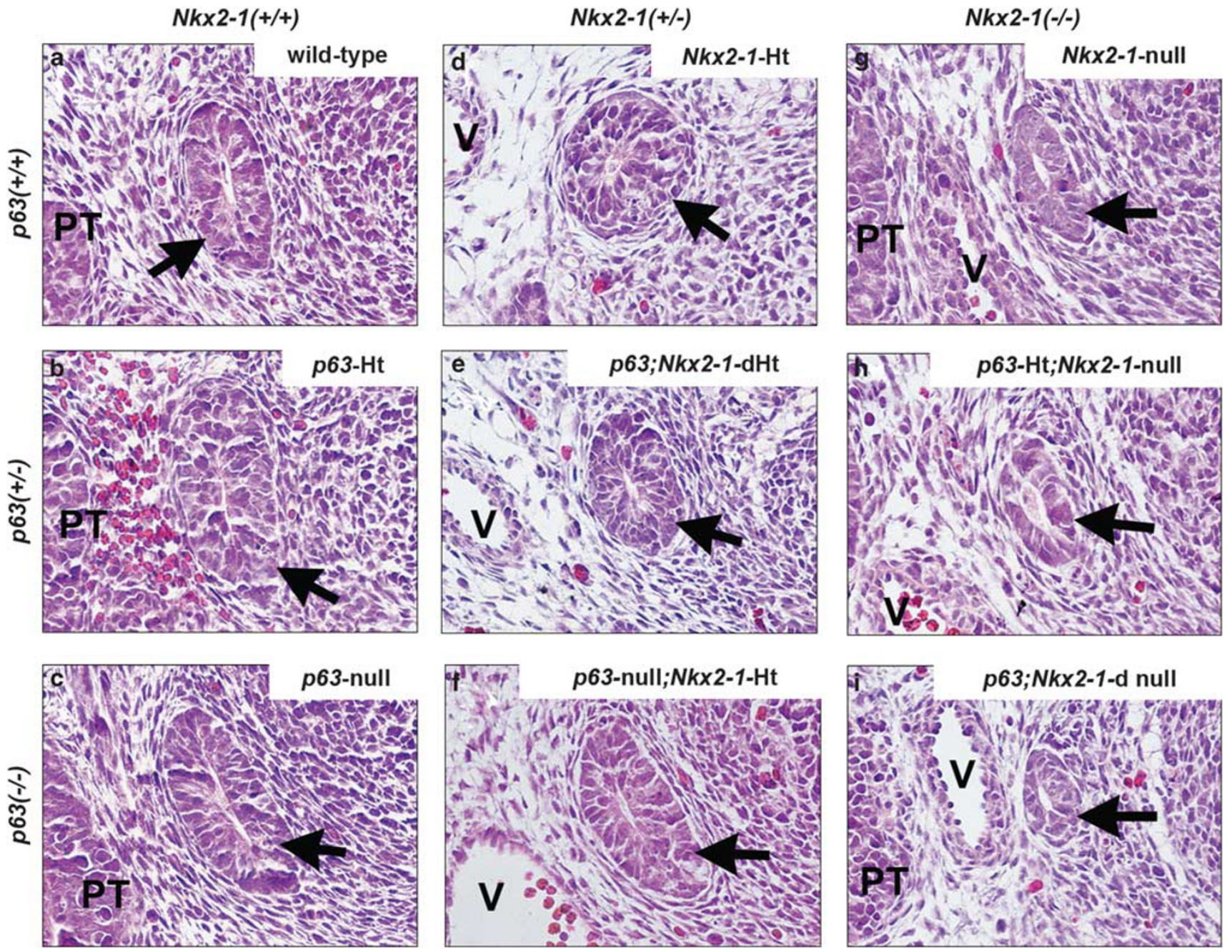

Figure 1 Ultimobranchial body (UBB) of E12.5 mouse embryos. Transverse sections are shown. (a-i) Each panel shows representative UBB (indicated by an arrow) from mice with various combinations of $p 63$ and Nkx2-1 alleles as indicated. PT: parathyroid, V: vessel. Magnification: $\times 400$. 

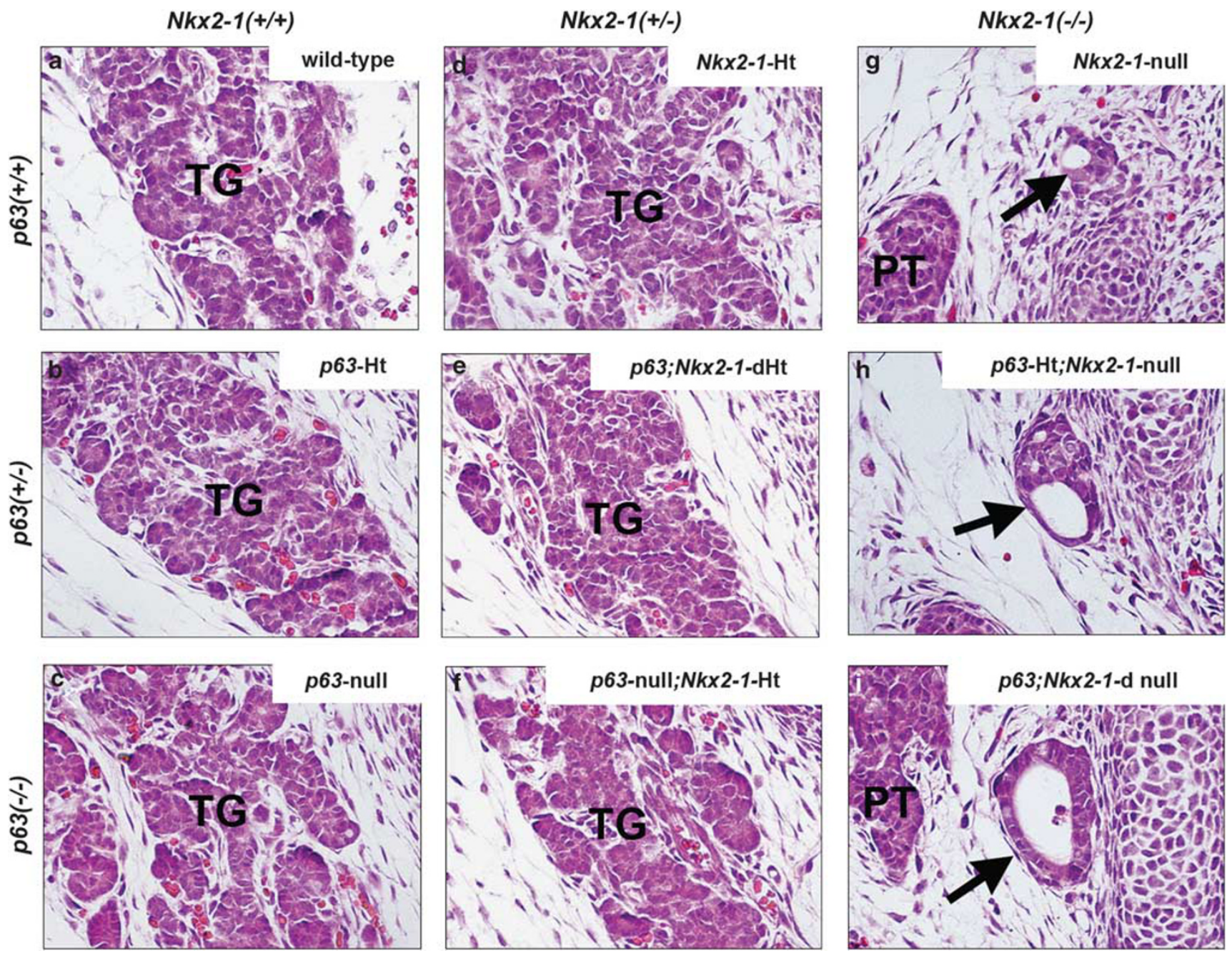

Figure 2 Thyroid gland and ultimobranchial body (UBB) of E14.5 mouse embryos. Frontal sections are shown. (a-f) Each panel shows representative thyroid (TG) from mice with various combinations of $p 63$ and Nkx2-1 wild-type or Ht alleles as shown. (g-i) Each panel shows representative UBB cyst (indicated by an arrow) from mice with three different combinations of $p 63$ and Nkx2-1-null alleles as shown. PT: parathyroid. It is to be noted that each size of UBB cyst seems to be different because of section's orientation. Magnification: $\times 400$.

indistinguishable. These results indicate that the development of UBB does not require either NKX2-1 or p63.

By E14.5 of mouse gestation, thyroid primordium cells meet with UBB cells, forming the thyroid gland. ${ }^{1-5}$ Indeed, both wild-type and Nkx2-1-Ht mice formed a thyroid gland composed of cells in trabecular or microfollicular patterns, regardless of the presence of the $p 63$ allele (Figures $2 \mathrm{a}-\mathrm{f}$ ). As gestation proceeded, the thyroids from six different combinations of Nkx2-1 (wild-type and $\mathrm{Ht}$ ) and p63 alleles (wildtype, Ht, and null) further increased in size, and by E18.5, many immature follicles of small and/or various sizes were clearly visible, in which colloid was present (Figures $3 a-f$ ). No significant histological differences in terms of size, follicle formation, and the presence of C-cells were found among these six different genotype thyroids. As the thyroid primordium of Nkx2-1-null mice starts degenerating around E10.5, ${ }^{16}$ no thyroid with follicular forming cells and C-cells was found in mice carrying $N k x 2-1$-null allele. Instead, the UBB remained in tubular or cystic patterns, which was found even in the p63;Nkx2-1-double-null mutants (Figures $2 \mathrm{~g}-\mathrm{i}$ and $3 \mathrm{~g}-\mathrm{l})$. By E18.5, the UBB consisted of increased number of cells (Figures $3 \mathrm{~g}-\mathrm{i}$ vs $\mathrm{j}-\mathrm{l}$ ), which appeared dilated with monolayer of cells in tubular structure in the p63;Nkx2-1double-null embryos (Figure 3i). Occasionally ciliated cells were found in the UBB cysts (Figures $3 \mathrm{~g}-\mathrm{l}$ ). These results show that p63 is not required for the development of thyroid gland and further suggest that cells in the p63;Nkx2-1-double-null UBB cyst resemble to those found in the SCN having occasional cilia. ${ }^{18-20}$

To examine whether $\mathrm{p} 63$ has any role in the function of thyroid, E17.5 embryonic thyroids from wild-type, p63-Ht, and p63-null mice were subjected to immunohistochemitry for thyroglobulin and calcitonin (Figure 4). Thyroid starts producing thyroid hormone around E15.,12 Thyroglobulin 

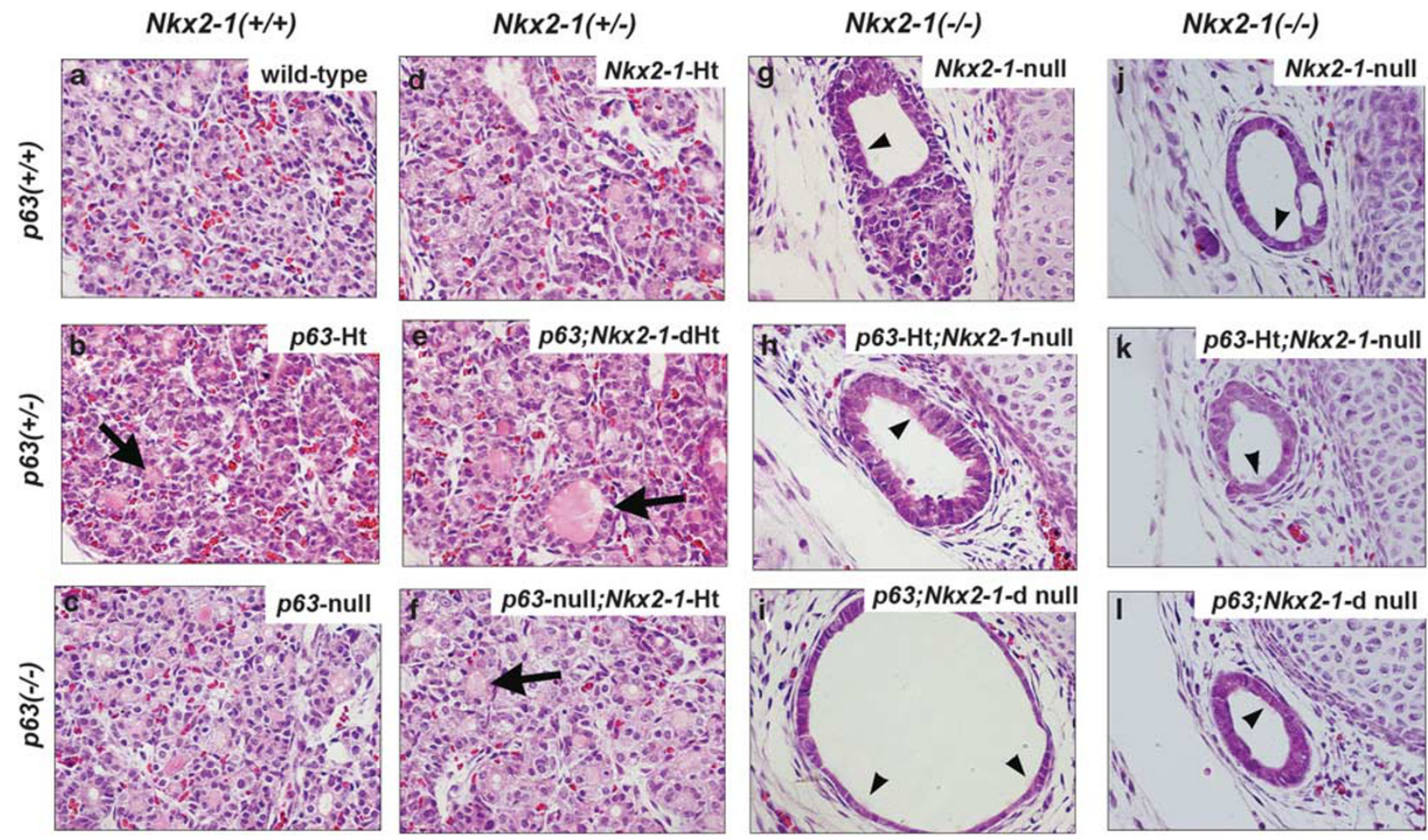

E17.5

E18.5

Figure 3 Thyroid and/or ultimobranchial body (UBB) cyst of mouse embryos at E17.5 and E18.5. Frontal sections are shown. (a-f) Each panel shows a representative thyroid from E18.5 mice with various combinations of $p 63$ and Nkx2-1 wild-type or Ht alleles as shown. Many small follicles are present, some of which contain colloid (seen in pink color, indicated by an arrow). (g-I) Each panel shows representative UBB cyst from E18.5 (g-i) and E17.5 (j-I) mice with three different combinations of p63 and Nkx2-1-null alleles as shown. Inside cysts, occasional ciliated cells are found (indicated by an arrowhead).

Magnification: $\times 400$.

was highly expressed in the thyroids of wild-type, and $p 63-\mathrm{Ht}$ and null mice at similar immunohistochemical intensity (Figures $4 a-c)$. Further, calcitonin was clearly detected in parafollicular cells of all three thyroids at similar extent (Figures $4 \mathrm{~d}-\mathrm{f}$ ). These results show that p63 may not be essential for the function of thyroid.

To further characterize the UBB cysts, expression of p63 was next examined. It was reported that NKX2-1 is strongly expressed in the UBB of normal mouse embryos at E11.5$13.5,{ }^{5,11,14,15}$ while p63-positive cells are scarce. ${ }^{5}$ In $N k x 2-1$-null mice, p63 expression was detected in a very small number of cells in E12.5 UBB (Figure 5a), while the expression was found in more cells as the gestational age increased (Figures 5b, c, e, and $\mathrm{f}$ ). At later gestational ages, the p63-expressing cells were located either at the outer layer surrounding the vesicular structure (Figure 5b, c, e and f) or uniformly situated in the cystic structure (Figure 5e). This compartmentalized p63 staining is strikingly similar to those found in the $\mathrm{SCN} .{ }^{18-20} \mathrm{No}$ expression of p63 was observed in the UBB cysts in mice carrying p63-null allele as expected (Figures $5 \mathrm{~d}$ and $\mathrm{g}$ ). It is to be noted that low levels of p63 expression were found in normal mouse thyroids (Figure 5h). This was in contrast to humans, in which no expression of p63 was reported. ${ }^{23-25}$
To further characterize the $p 63 ; N k x 2-1$-double-null UBB cysts, immunohistochemistry was next carried out using antibodies for NSE (neuron-specific enolase) and S100 as neuron-specific markers, Oct 4 as a stem cell marker, nestin and SOX10 as a neural crest marker, and vimentin as a mesenchymal marker. Positive staining was not found with any of the antibodies examined in E12.5, 14.5, and 17.5 embryos (data not shown). When E14.5 p63;Nkx2-1-double-null UBB was subjected to electron microscopic examination, irregular shaped cells with scarce cytoplasm and fairly modestly electron dense nucleus were found (Figure 6b). Further, no clear intracellular organelles or adhesion structures were found. This was in sharp contrast to wild-type thyroid follicular cells, in which mitochondria, rough endoplasmic reticulum, tight junction, and desmosome were clearly observed. (Figure 6a). These results show that cells in the p63;Nkx2-1double-null UBB are very poorly developed.

\section{DISCUSSION}

In this study, we showed using mice with various combinations of p63 and Nkx2-1 alleles, that p63 is not required for thyroid development and function. Further, UBB remains as a tubular structure even without $N k \times 2-1$ and $p 63$ alleles, 
$\operatorname{Tg}$
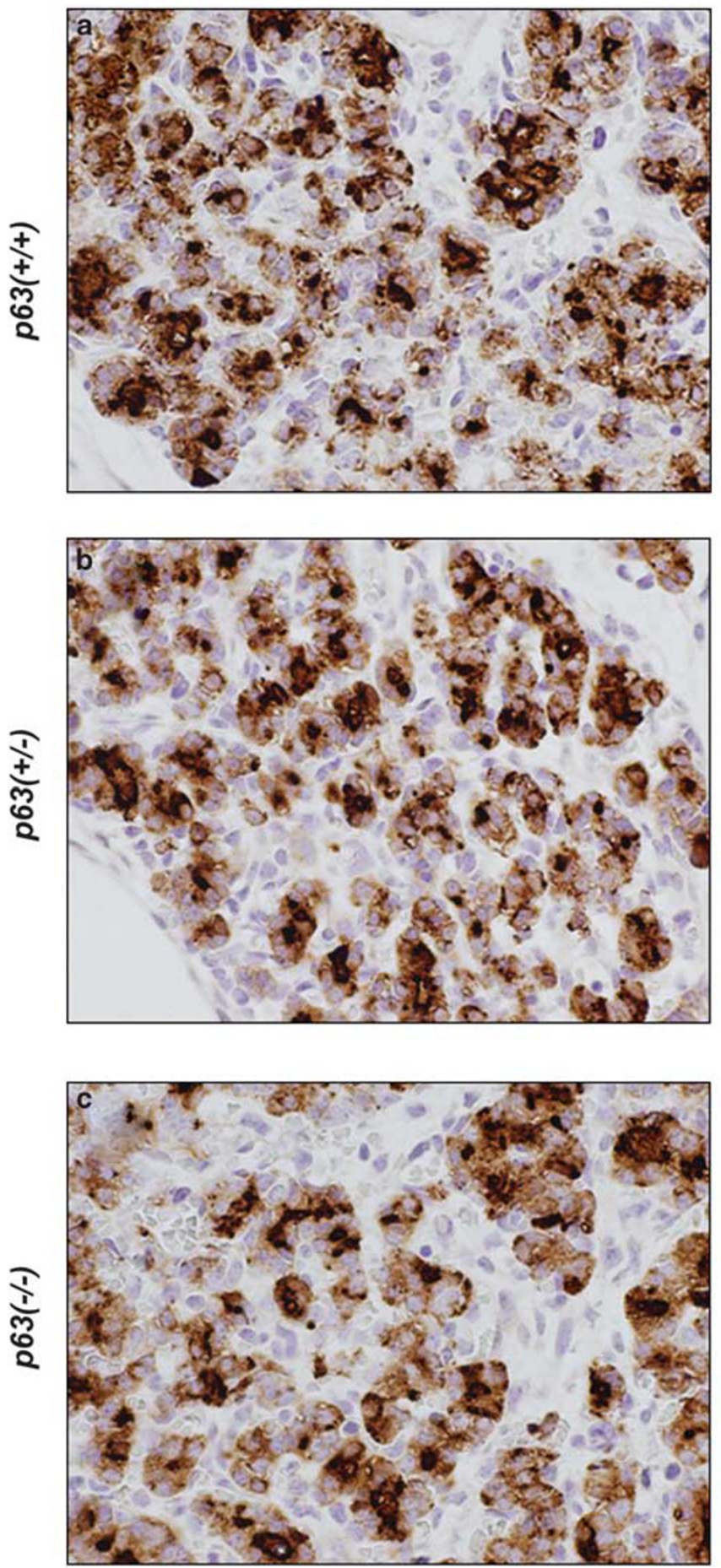

CT
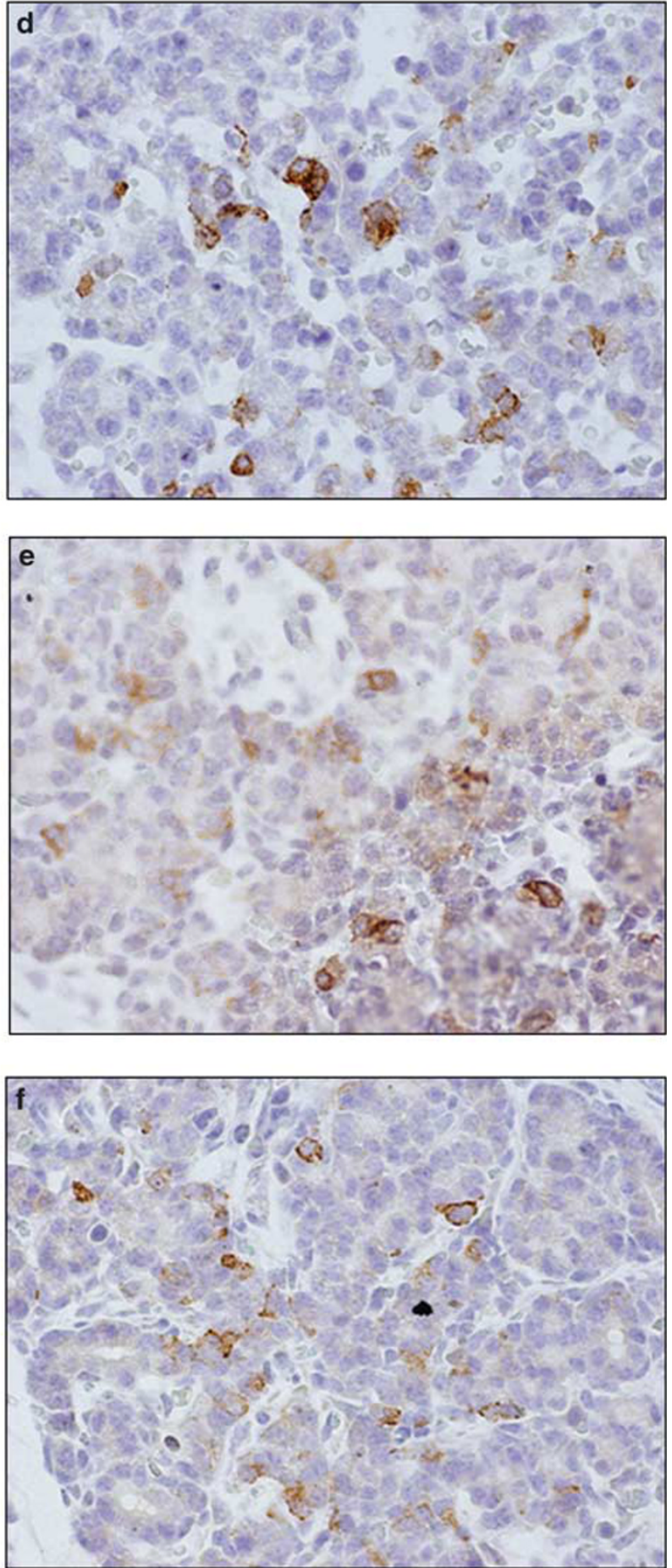

Figure 4 Thyroglobulin and calcitonin expression in E17.5 thyroid from mice with three different p63 alleles. Nkx2-1 allele is wild-type. Both thyroglobulin $(\mathrm{Tg}, \mathbf{a}-\mathbf{c})$ and calcitonin (CT, $\mathbf{d}-\mathbf{f})$ expression are found equally in distribution and intensity in three different genotype mouse thyroids by immunohistochemistry. Positives are shown in brown color. Magnification: $\times 400$.

whose cells are poorly developed as shown by electron microscope. This indicates that UBB consists of three types of cells; those expressing NKX2-1 and p63, and immature cells not expressing either gene. As calcitonin is expressed in p63-null mouse thyroids, NKX2-1-positive UBB cells may be the origin of $\mathrm{C}$ cells. In fact, the expression of NKX2-1 was previously reported in $\mathrm{C}$ cells. ${ }^{32}$ Sometimes, ciliated cells are found in the UBB cells. In the presence of p63 as found in the 


\section{Nkx2-1-null UBB Cyst}
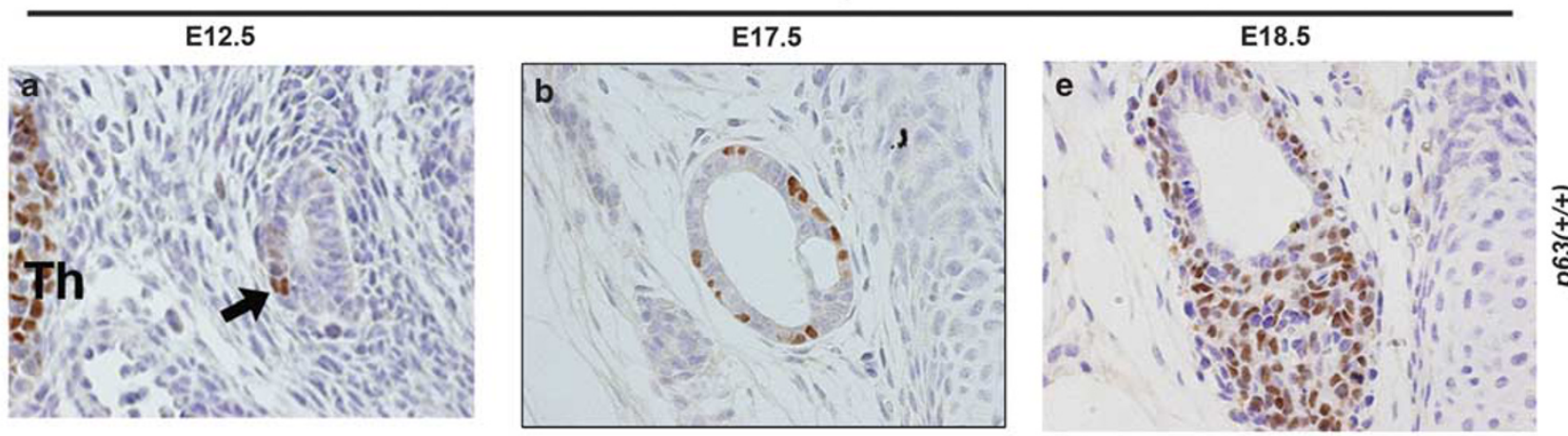

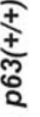
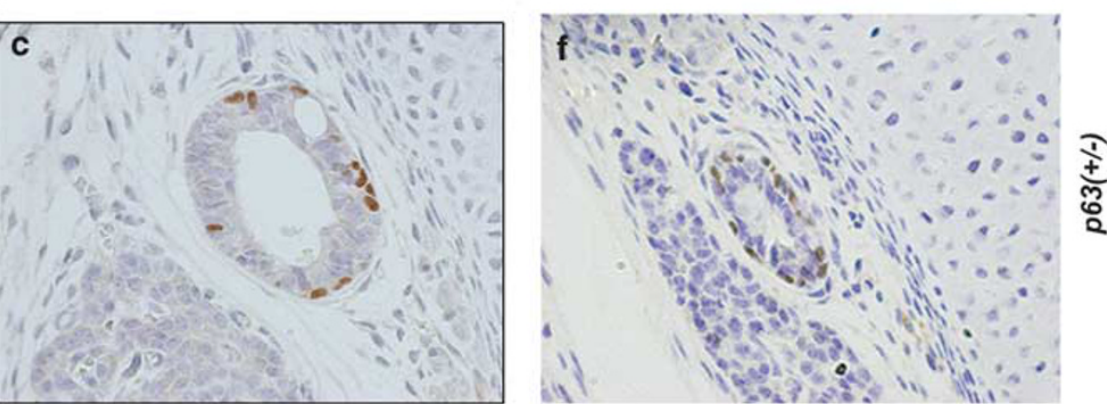

E17.5 wt TG
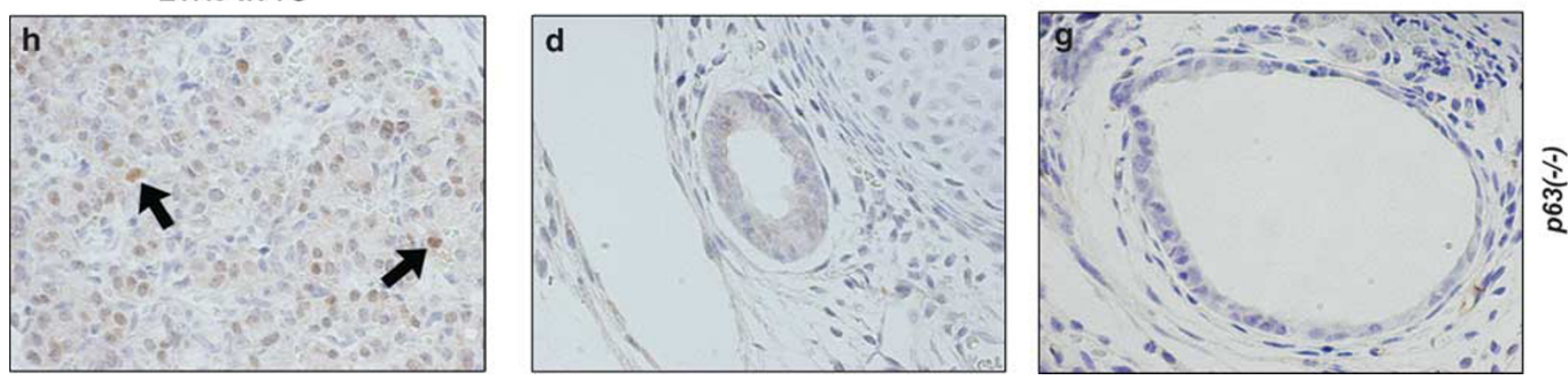

Figure 5 p63 expression in the Nkx2-1-null mouse ultimobranchial body (UBB) cyst. p63-positive cells in UBB of E12.5 Nkx2-1-null mouse (a) and E17.5 normal mouse thyroid (h, TG) are shown by an arrow. Thm: thymus. p63-positive cells in E17.5 (b-d) and E18.5 (e-g) Nkx2-1-null mouse UBBs with various p63 genotypes are observed outside of vesicular structure $(\mathbf{b}, \mathbf{c}, \mathbf{e}, \mathbf{f})$ or solid cystic pattern of cells $(\mathbf{e})$. It is to be noted that the size of UBB appears to look smaller in (f) because of orientation of the section. Magnification: $\times 400$.

Nkx-2-1-null and p63-Ht;Nkx2-1-null mice, the cystic structure of UBB is surrounded by p63-positive outer layer of cells, which sometimes continued to p63-positive cells in nested pattern. This compartmentalized p63-positive structure strikingly resembles the SCN in humans. The SCN is present in most human thyroids. ${ }^{21}$ It contains both solid cell proliferation and cyst-like structures, having strong p63-positive cells at the periphery with centrally located p63-negative cells of unknown phenotype. ${ }^{18-20}$ The occasional presence of ciliated cells is noted. ${ }^{18-20}$ Furthermore, the presence of second kind of follicle in so-called mixed follicles has been known for decades in normal rats and mice. ${ }^{33}$ This second kind of follicle is characterized by a nonhomogeneous or foamy colloid and the presence of occasional ciliated cells, ${ }^{33}$ and is thought to originate from the UBB. ${ }^{34}$ Taken together, the p63;Nkx2-1-double-null UBB cyst may indeed be the origin of SCN in humans and the second kind of follicles in rats and mice.

The p63;Nkx2-1-double-null UBB cells appeared to be undifferentiated at least when examined at E14.5 by electron microscope. In particular, the presence of scarce narrow cytoplasm (high ratio of nucleus/cytoplasm) and moderately electron dense nucleus with clumps of nuclear heterochromatin is reported for immature cells and undifferentiated ES cells. ${ }^{35-37}$ This could be the reason that no positive immunoreactivity was obtained with the antibodies examined (NSE, S100, Oct 4, nestin, SOX10, and vimentin). Thus, the p63;Nkx2-1-double-null UBB cells may represent immature stem-like cells. If they are stem-like cells, one may expect the expression of Oct 4 . However, Oct 4 expression was not detected in the p63;Nkx2-1-double-null UBB cells by immunohistochemitry. Oct 4 protein is expressed in 

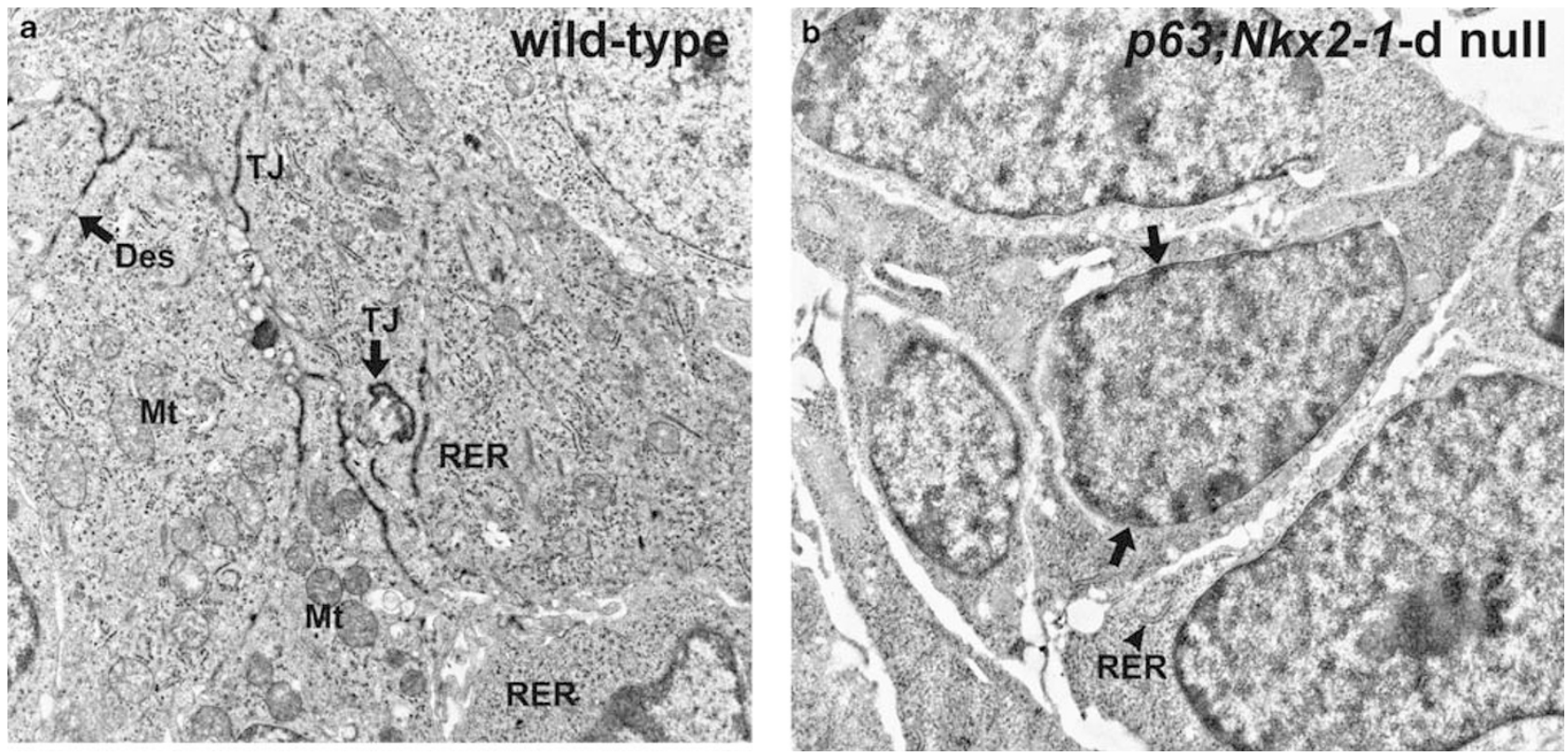

Figure 6 Electron microscopic analysis. Representative electron microscopic images of E14.5 wild-type thyroid (a) and p63;Nkx2-1-d null mouse ultimobranchial body (UBB) cyst (b) are shown. (a) Many intracellular organelles and cell attachments are clearly observed as dense membranes. Numerous cytoplasmic organella are well developed in the immature follicular cells at this embryonic stage. No colloid formation is shown but surrounded by well developed tight junctions. A few microvilli are observed. Des: desmosome, Mt: mitochondria, RER: rough endoplasmic reticulum, TJ: tight junction. (b) Very scant intracellular organella is observed. RER are minimally found (shown by an arrowhead). Clumps of nuclear heterochromatin are indicated by arrows. Magnification: $\times 3000$.

embryonic/primordial germ and embryonic stem cells. Although some reports have described Oct 4 expression in adult normal stem cells and tumors, they are mainly determined by RT-PCR, but not by detection of protein such as immunohistochemistry or western blotting. ${ }^{38,39}$

The undifferentiated UBB cells may correspond to cells found in SCN that were described by Burstein et al ${ }^{18}$ as centrally located p63-negative cells of unknown phenotype. Previously, electron microscopic study showed that many desmosomes and hemidesmosomes are present in SCN, however, these cell adhesion structures and their cytoplasmic organella are poorly developed. ${ }^{40}$ As p63 is used as a marker for the SCNs, ${ }^{18-20,24}$ it seems that the undifferentiated UBB cells are always associated with the p63-positive cells. In this regard, it is interesting to note that p63 is expressed in the basal/stem cells of several types of epithelia such as skin, esophagus, urethra, and secretory epithelial tissues including lacrimal, mammary, and prostate glands. ${ }^{41-46}$ On the basis of these studies together with those of p63-null mice, ${ }^{41,42}$ it was suggested that p63 has a role in commitment, maintenance, and differentiation of epithelial cells. It was reported that a subset of papillary thyroid carcinoma and Hashimoto's thyroiditis are often associated with the SCN and express high levels of p63. ${ }^{18,22,25-27}$ Further, ciliated cells are occasionally identified in some histological types of follicular cell neoplasms. ${ }^{47}$ Whether the basal/stem cell characteristics of p63-expressing cells together with the associated undifferentiated cells have any role in the pathogenesis of SCN-associated lesions such as papillary thyroid carcinoma and Hashimoto's thyroiditis requires further experimentation.

On the basis of the fact that almost all normal human fetal thyroids have $\mathrm{SCN},{ }^{21}$ at least two questions arise. Why and for what purpose do the SCN originating from cystic UBB cells remain in the thyroid, and whether they stay dormant throughout adult life or disintegrate at some point, most notably after birth. What is the nature of the undifferentiated UBB cells? Additional studies are required to address these questions and firmly establish correlations with development of thyroid lesions if there are any.

\section{ACKNOWLEDGEMENTS}

We thank Drs Alea Mills (Cold Spring Harbor Laboratory) for providing us p63(fl/fl) mice and Frank Gonzalez (NCl) for his critical review of the paper This work was supported by Intramural Research Program of the National Cancer Institute, Center for Cancer Research.

\section{DISCLOSURE/CONFLICT OF INTEREST}

The authors declare no conflict of interest.

1. Biddinger PW, Ray M. Distribution of $C$ cells in the normal and diseased thyroid gland. Pathol Annu 1993;28:205-229.

2. Di Lauro R, De Felice M. Thyroid Gland: Anatomy and Development. Saunders: Philadelphia, 2001.

3. Kaufman M, Bard J. The Anatomical Bases of Mouse Development. Academic Press: London, 1999.

4. Manley NR, Capecchi MR. Hox group 3 paralogs regulate the development and migration of the thymus, thyroid, and parathyroid glands. Dev Biol 1998;195:1-15. 
5. Kusakabe T, Hoshi N, Kimura S. Origin of the ultimobranchial body cyst: T/ebp/Nkx2.1 expression is required for development and fusion of the ultimobranchial body to the thyroid. Dev Dyn 2006;235:1300-1309.

6. Kameda Y. Immunocytochemical localization and development of multiple kinds of neuropeptides and neuroendocrine proteins in the chick ultimobranchial gland. J Comp Neurol 1991;304:373-386.

7. Miura M, Kameda Y. Neuronal properties in cultured ultimobranchial $C$ cells of chick embryos: process outgrowth and expression of TuJ1 and enkephalin. Brain Res 2001;905:1-11.

8. Kameda Y, Nishimaki T, Chisaka O, et al. Expression of the epithelial marker E-cadherin by thyroid $C$ cells and their precursors during murine development. J Histochem Cytochem 2007;55:1075-1088.

9. Mizuno K, Gonzalez FJ, Kimura S. Thyroid-specific enhancer-binding protein (T/EBP): cDNA cloning, functional characterization, and structural identity with thyroid transcription factor TTF-1. Mol Cell Biol 1991;11:4927-4933.

10. Guazzi S, Price M, De Felice $M$, et al. Thyroid nuclear factor 1 (TTF-1) contains a homeodomain and displays a novel DNA binding specificity. EMBO J 1990;9:3631-3639.

11. Kimura S, Hara Y, Pineau T, et al. The T/ebp null mouse: thyroid-specific enhancer-binding protein is essential for the organogenesis of the thyroid, lung, ventral forebrain, and pituitary. Genes Dev 1996;10:60-69.

12. De Felice M, Di Lauro R. Thyroid development and its disorders: genetics and molecular mechanisms. Endocr Rev 2004;25:722-746.

13. Kusakabe T, Kawaguchi A, Hoshi N, et al. Thyroid-specific enhancerbinding protein/NKX2.1 is required for the maintenance of ordered architecture and function of the differentiated thyroid. Mol Endocrinol 2006;20:1796-1809.

14. Mansouri A, Chowdhury K, Gruss P. Follicular cells of the thyroid gland require Pax8 gene function. Nat Genet 1998;19:87-90.

15. Kameda $Y$, Ito $M$, Nishimaki $T$, et al. FRS2alpha is required for the separation, migration, and survival of pharyngeal-endoderm derived organs including thyroid, ultimobranchial body, parathyroid, and thymus. Dev Dyn 2009;238:503-513.

16. Kimura S, Ward JM, Minoo P. Thyroid-specific enhancer-binding protein/thyroid transcription factor 1 is not required for the initial specification of the thyroid and lung primordia. Biochimie 1999;81:321-327.

17. Cameselle-Teijeiro J, Varela-Duran J, Sambade C, et al. Solid cell nests of the thyroid: light microscopy and immunohistochemical profile. Hum Pathol 1994;25:684-693.

18. Burstein DE, Nagi C, Wang BY, et al. Immunohistochemical detection of p53 homolog p63 in solid cell nests, papillary thyroid carcinoma, and hashimoto's thyroiditis: a stem cell hypothesis of papillary carcinoma oncogenesis. Hum Pathol 2004;35:465-473.

19. Reis-Filho JS, Preto A, Soares $P$, et al. p63 expression in solid cell nests of the thyroid: further evidence for a stem cell origin. Mod Pathol 2003; 16:43-48.

20. Preto A, Cameselle-Teijeiro J, Moldes-Boullosa J, et al. Telomerase expression and proliferative activity suggest a stem cell role for thyroid solid cell nests. Mod Pathol 2004;17:819-826.

21. Harach HR, Vujanic GM, Jasani B. Ultimobranchial body nests in human fetal thyroid: an autopsy, histological, and immunohistochemical study in relation to solid cell nests and mucoepidermoid carcinoma of the thyroid. J Pathol 1993;169:465-469.

22. Malaguarnera $R$, Vella $V$, Vigneri $R$, et al. p53 family proteins in thyroid cancer. Endocr Relat Cancer 2007;14:43-60.

23. Malaguarnera R, Mandarino A, Mazzon E, et al. The p53-homologue p63 may promote thyroid cancer progression. Endocr Relat Cancer 2005;12:953-971.

24. Reimann JD, Dorfman DM, Nose V. Carcinoma showing thymus-like differentiation of the thyroid (CASTLE): a comparative study: evidence of thymic differentiation and solid cell nest origin. Am J Surg Pathol 2006;30:994-1001.
25. Unger $\mathrm{P}$, Ewart $\mathrm{M}$, Wang $\mathrm{BY}$, et al. Expression of $\mathrm{p} 63$ in papillary thyroid carcinoma and in Hashimoto's thyroiditis: a pathobiologic link? Hum Pathol 2003;34:764-769.

26. Cameselle-Teijeiro J, Abdulkader I, Perez-Becerra R, et al. BRAF mutation in solid cell nest hyperplasia associated with papillary thyroid carcinoma. A precursor lesion? Hum Pathol 2009;40:1029-1035.

27. Asioli S, Erickson LA, Lloyd RV. Solid cell nests in Hashimoto's thyroiditis sharing features with papillary thyroid microcarcinoma. Endocr Pathol 2009;20:197-203.

28. Mills AA, Qi Y, Bradley A. Conditional inactivation of p63 by Cremediated excision. Genesis 2002;32:138-141.

29. Lakso M, Pichel JG, Gorman JR, et al. Efficient in vivo manipulation of mouse genomic sequences at the zygote stage. Proc Natl Acad Sci USA 1996;93:5860-5865.

30. Koster MI, Kim S, Mills AA, et al. p63 is the molecular switch for initiation of an epithelial stratification program. Genes Dev 2004;18:126-131.

31. Hayat MA. Principles and Techniques of Electron Microscopy, Biological Applications, Vol. 1 Van Nostranc Reinhold: New York, 1970.

32. Suzuki K, Kobayashi $\mathrm{Y}$, Katoh $\mathrm{R}$, et al. Identification of thyroid transcription factor- 1 in $\mathrm{C}$ cells and parathyroid cells. Endocrinology 1998;139:3014-3017.

33. Wollman SH, Neve P. Ultimobranchial follicles in the thyroid glands of rats and mice. Recent Prog Horm Res 1971;27:213-234.

34. Wollman SH, Hilfer SR. Embryologic origin of the various epithelial cell types in the second kind of thyroid follicle in the $\mathrm{C} 3 \mathrm{H}$ mouse. Anat $\mathrm{Rec}$ 1978;191:111-121.

35. Ngwenya LB, Rosene DL, Peters A. An ultrastructural characterization of the newly generated cells in the adult monkey dentate gyrus. Hippocampus 2008;18:210-220.

36. Nabarra B, Mulotte $M$, Casanova $M$, et al. Ultrastructural study of the FVB/N mouse thymus: presence of an immature epithelial cell in the medulla and premature involution. Dev Comp Immunol 2001;25: 231-243.

37. Sathananthan AH, Nottola SA. Digital imaging of stem cells by electron microscopy. Methods Mol Biol 2007;407:21-41.

38. Looijenga LH, Stoop H, de Leeuw HP, et al. POU5F1 (OCT3/4) identifies cells with pluripotent potential in human germ cell tumors. Cancer Res 2003;63:2244-2250.

39. Trosko JE. From adult stem cells to cancer stem cells: Oct-4 gene, cellcell communication, and hormones during tumor promotion. Ann NY Acad Sci 2006;1089:36-58.

40. Kakudo K, Kitamura H, Miyauchi A, et al. Squamous metaplasia of human thyroid gland-an electron microscopic study of sold cells nest. Med J Osaka Univ 1977;28:33-38.

41. Mills AA, Zheng $B$, Wang $X J$, et al. p63 is a p53 homologue required for limb and epidermal morphogenesis. Nature 1999;398: 708-713.

42. Yang A, Schweitzer R, Sun D, et al. p63 is essential for regenerative proliferation in limb, craniofacial and epithelial development. Nature 1999;398:714-718.

43. Di Como CJ, Urist MJ, Babayan I, et al. p63 expression profiles in human normal and tumor tissues. Clin Cancer Res 2002;8:494-501.

44. Reis-Filho JS, Schmitt FC. Taking advantage of basic research: p63 is a reliable myoepithelial and stem cell marker. Adv Anat Pathol 2002;9:280-289.

45. Kurita T, Medina RT, Mills AA, et al. Role of p63 and basal cells in the prostate. Development 2004;131:4955-4964.

46. McKeon F. p63 and the epithelial stem cell: more than status quo? Genes Dev 2004;18:465-469.

47. Ando M, Nakanishi $Y$, Asai $M$, et al. Mucoepidermoid carcinoma of the thyroid gland showing marked ciliation suggestive of its pathogenesis. Pathol Int 2008;58:741-744. 